Voix et Images

voixetimages

\title{
Mourir à tue-tête, un film d'Anne-Claire Poirier
}

\section{Gilles Thérien}

Volume 5, numéro 3, printemps 1980

Fernand Ouellette

URI : https://id.erudit.org/iderudit/200235ar

DOI : https://doi.org/10.7202/200235ar

Aller au sommaire du numéro

Éditeur(s)

Les Presses de l'Université du Québec

ISSN

0318-9201 (imprimé)

1705-933X (numérique)

Découvrir la revue

Citer ce compte rendu

Thérien, G. (1980). Compte rendu de [Mourir à tue-tête, un film d'Anne-Claire

Poirier]. Voix et Images, 5(3), 583-584. https://doi.org/10.7202/200235ar d'utilisation que vous pouvez consulter en ligne.

https://apropos.erudit.org/fr/usagers/politique-dutilisation/ 


\section{Mourir à tue-téte, un film d'Anne-Claire Poirier}

Précaution d'usage et non inutile: je suis un homme. II ne m'est donc pas donné de comprendre ce qu'est un viol dans la société phallocratique que mes semblables ont édifiée. Tout au plus, puis-je en avoir une certaine perception mais les avertissements sévères servis tout au long du film m'empêchent de prétendre à quoi que ce soit au plan du contenu. C'est donc le traitement du sujet qui guidera mes réflexions. Ce film est un long métrage, c'est-à-dire qu'il prétend non seulement à un certain format dans le temps (plus de 90 minutes) mais encore à un cadre où la fiction a droit de cité. Le début du film remplit très bien ces conditions. Nous assistons à la mise en scène d'un viol particulièrement violent que la cinéaste a traité avec beaucoup de sensibilité en ne versant pas carrément dans le voyeurisme. L'esthétique du montage, fondus colorés et rapides, accentue le caractère dramatique d'une action qui charrie d'elle-même toute sa force. Et soudainement l'image se fige sur la figure grimaçante de plaisir et de violence de l'homme pour nous ramener dans une salle de montage où la réalisatrice et sa monteuse discutent des images du film. Nous basculons soudainement dans une fiction fortement appuyée sur le documentaire de type "cinéma-vérité". Ici encore, nous avons des comédiens mais ils prennent la relève immédiate de la véritable réalisatrice et de son monteur. Questions et réponses sont artificielles. Des fils invisibles manipulent les mots mais le cœur n'y est pas. Les surprises, les questionnements sont feints et portent en eux la trace d'un discours obligato venant de la déesse derrière la machine.

Dans l'espace d'une quinzaine de minutes, nous sommes donc confrontés à un premier changement de style qui servira au cours du film de rappel, de charnière actantielle des moments narratifs. Puis la fiction reprend et sera coupée cette fois de scènes de guerre et même d'un rituel d'excision du clitoris. Les scènes d'archives sont mêlées à des scènes fictives tournées à la manière d'archives. De l'événement particulier, nous sommes transportés aux méfaits de la guerre, aux rituels primitifs. C'est le documentairedocument qui épouse ici les formes de la fiction. Ces trois formes vont maintenant se mêler et progresser: l'histoire individuelle du viol sera doublée de considérations plus générales, plus abstraites et aussi plus englobantes que le seul thème du viol d'une femme. 
Quand les archives font défaut, quand l'illustration devient déficiente comme c'est le cas du code criminel en matière d'attentats sexuels, fiction et document font place à une dramatisation théâtrale d'un pseudo-procès de tous les délits sexuels commis contre la femme. Et puis, la trame narrative reprend. Nous suivons l'évolution vers le silence de la victime, Suzanne. Ce silence qui émerge tout naturellement de l'acte lui-même vient enfermer la victime qui trouvera un dernier refuge dans la mort lorsque les sons n'auront mème plus leur place dans sa bouche. Le film se termine par une curieuse évocation des moyens dérisoires dont dispose la femme pour se défendre: tous les lieux de la ville sont marqués par les sifflets de détresse des femmes assaillies.

Personne ne peut nier la force du sujet traité, encore moins de sa pertinence. Hommes et femmes peuvent utilement réfléchir sur ce qui ne vaut bien souvent qu'une petite manchette dans un journal à sensation. Cela seul pourrait expliquer le succès que connaît ce film. Pourtant la construction du film crée un malaise. Non pas celui, légitime, de celui qui dérange mais le sentiment que le film en dit à la fois trop et pas assez. Il est difficile de ne pas percevoir l'introduction de la réalisatrice et de sa monteuse comme un moyen de justifier un discours qui se veut trop global. L'exemple est particulièrement clair dans le cas de la chevelure qu'il est, un instant, question de couper. L'extrapolation à la tonte est difficile à assurer d'autant plus qu'elle laisse de côté, volontairement ou non, toute une partie de ce «rituel». Bien sûr les coupables, les condamnés sont tondus mais il en est de même à l'intérieur de la religion et la signification n'en est pas moins grande tout en étant librement consentie. Les archives qui étendent le problème du viol à celui de la violence dans les guerres réduisent en même temps tout ce que la guerre contient de pure violence et ne semblent jouer que sur le fait que dans "violence», on retrouve “viol". La guerre n'est pas qu'une manifestation phallocratique. Les affirmations sur le fait que seule l'espèce humaine s'adonne au viol, en plus d'être fausses, induisent le spectateur à croire à une distinction, à une rupture entre l'homme et l'animal, vieille idée héritée du catholicisme et qui est la source d'une surévaluation de la culture... Enfin, l'affirmation que tout être qui a un vagin ne peut compter que sur un sifflet pour se défendre cadre mal dans une société rompue au sifflet des policiers ou à ceux des arbitres qui scandent les performances sportives.

Ce film-choc oscille entre la déclamation et l'expression d'une situation. La réalisatrice n'a pas su choisir entre ces deux pôles, ce qui nous amène à passer d'un discours militant, parfois grossier, à une expression très sensible où l'on sent se profiler le silence final. Mourir à tue-tête est un discours en pièces détachées. Chacun pourra y retrouver sa petite partie, on ne peut que déplorer que le traitement ne soit pas aussi fort, aussi inexorable que la situation. Mais le dilemme demeure: en parlant du viol, faut-il "violer" aussi la conscience du spectateur ou chercher à l'éduquer, qu'il soit homme ou femme? 